\title{
OPEN Engineering lithoheterotrophy in an obligate chemolithoautotrophic Fe(II) oxidizing bacterium
}

\begin{abstract}
Abhiney Jain \& Jeffrey A. Gralnick $\mathbb{D}$
Neutrophilic Fe(II) oxidizing bacteria like Mariprofundus ferrooxydans are obligate chemolithoautotrophic bacteria that play an important role in the biogeochemical cycling of iron and other elements in multiple environments. These bacteria generally exhibit a singular metabolic mode of growth which prohibits comparative "omics" studies. Furthermore, these bacteria are considered non-amenable to classical genetic methods due to low cell densities, the inability to form colonies on solid medium, and production of copious amounts of insoluble iron oxyhydroxides as their metabolic byproduct. Consequently, the molecular and biochemical understanding of these bacteria remains speculative despite the availability of substantial genomic information. Here we develop the first genetic system in neutrophilic Fe(II) oxidizing bacterium and use it to engineer lithoheterotrophy in $M$. ferrooxydans, a metabolism that has been speculated but not experimentally validated. This synthetic biology approach could be extended to gain physiological understanding and domesticate other bacteria that grow using a single metabolic mode.
\end{abstract}

Genetic studies have been primarily limited to colony-forming microorganisms that can grow using multiple metabolic strategies. The ability to form colonies on solid medium is advantageous for selection and screening of mutants, while metabolic flexibility allows for viability of mutants missing pathways of interest. However, the vast majority of microorganisms are not readily cultured on solid medium ${ }^{1}$ and many exhibit specialist lifestyles using a singular metabolic mode to grow ${ }^{2-8}$. Our overall hypothesis is that synthetic biology can be leveraged to better understand and domesticate environmental microorganisms with novel metabolic capabilities. To begin exploring this hypothesis, we focus on Mariprofundus ferrooxydans PV $-1^{3}$ that grows only by one metabolic mode, the oxidation of $\mathrm{Fe}$ (II) coupled to the reduction of oxygen while fixing carbon dioxide through a metabolism called chemolithoautotrophy.

Diverse neutrophilic chemolithoautotrophic bacteria have been known to oxidize Fe(II) in many circumneutral environments ${ }^{2,3,7,8}$. Understanding the metabolism and physiology of chemolithoautotrophic $\mathrm{Fe}$ (II) oxidizing bacteria is of environmental and ecological importance because of their widespread impact in various environments on multiple biogeochemical cycles including iron, carbon, nitrogen, phosphorous and other metals ${ }^{2,3,7-11}$. While a substantial amount of genomic information about chemolithoautotrophic Fe(II) oxidizing bacteria exists ${ }^{12-14}$, functional knowledge remains speculative in the absence of metabolic and genetic studies. Since atmospheric concentrations of oxygen rapidly react with $\mathrm{Fe}(\mathrm{II})$, chemolithoautotrophic Fe(II) oxidizing bacteria grow under microaerobic conditions $s^{2,3,7-11}$ where they catalyze oxidation of Fe(II) faster than oxygen. The requirement for this specific niche makes these microorganisms difficult to culture for laboratory studies. Furthermore, chemolithoautotrophic Fe(II) oxidizing bacteria are considered non-amenable to genetic methods because these bacteria do not grow on solid medium, produce low growth yields $\left(10^{6}-10^{7}\right.$ cells $\left./ \mathrm{mL}\right)$ and accumulate a substantial amount of insoluble iron oxyhydroxide as their obligate metabolic byproduct ${ }^{2-8}$. The inability to grow and form colonies on solid medium prevents the application of traditional genetic methods to select and screen for mutants. Low cell yield along with the presence of insoluble iron oxyhydroxide presents a formidable challenge for DNA transformation and subsequent phenotypic analysis to readily test genetic parts and methods. These bacteria are also generally metabolic specialists which grow by a singular metabolic mode of oxidizing $\mathrm{Fe}(\mathrm{II})$ as the energy source while fixing carbon dioxide and respiring low levels of oxygen ${ }^{2,3,7,8}$. The 

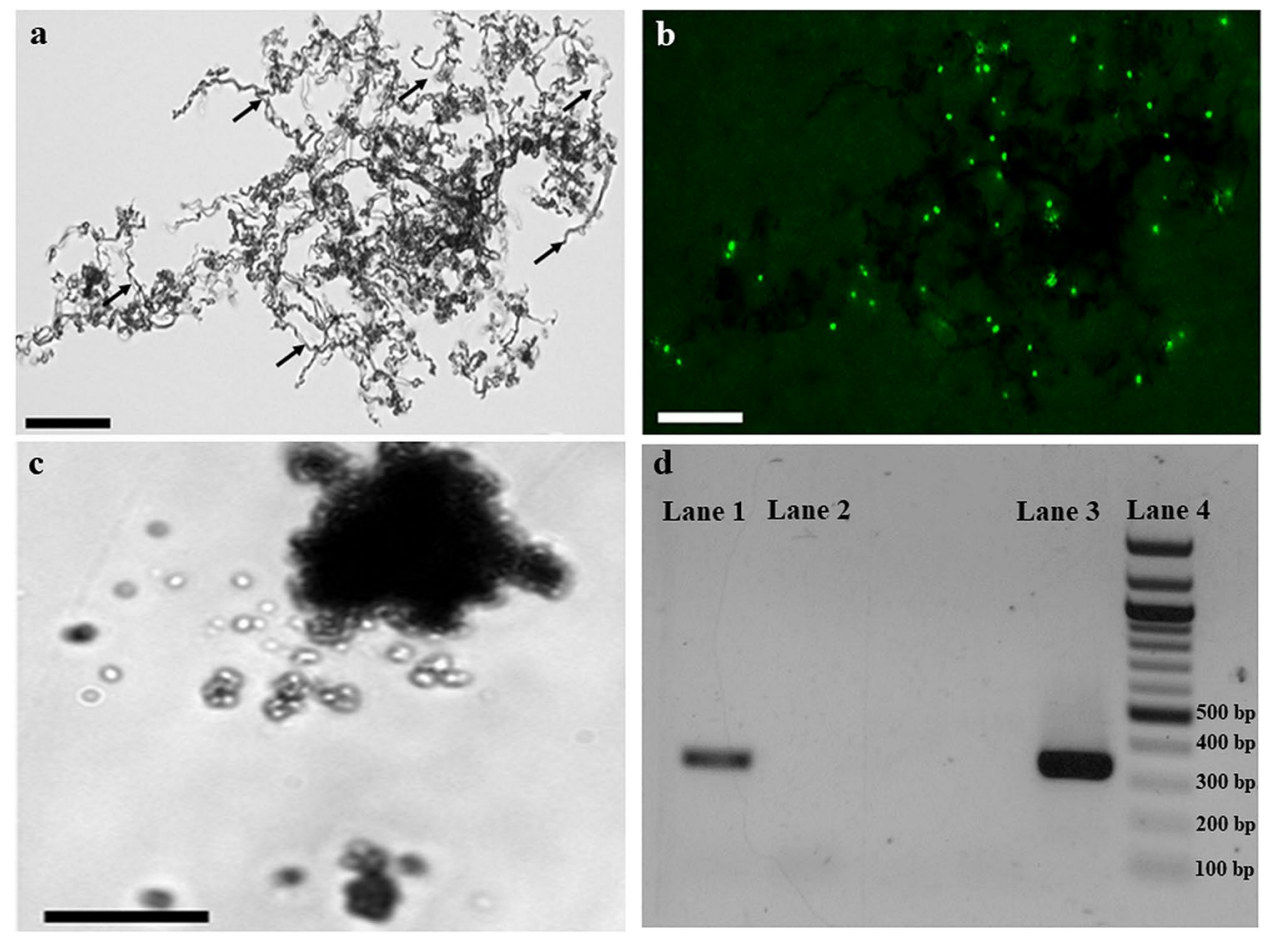

Figure 1. Transformation of $M$. ferrooxydans. Successful transformation of pRK2m3 (empty vector) into $M$. ferrooxydans was confirmed by (a) growth in the presence of $200 \mu \mathrm{g} / \mathrm{mL}$ kanamycin as shown by the production of characteristic stalk formation (black arrows) in the bright field micrograph and (b) an epifluorescent micrograph of the same field showing cells stained with Syto 9. (c) Wild-type cells were unable to grow or produce stalks in the presence of $200 \mu \mathrm{g} / \mathrm{mL}$ kanamycin and only formation of amorphous iron oxyhydroxides was observed. Scale bars indicate $25 \mu \mathrm{m}$. (d) Electropherogram showing amplification of pRK2m3 specific DNA fragment using DNA extracted from the transformed cells after ten transfers in the presence of $200 \mu \mathrm{g} / \mathrm{mL}$ kanamycin (Lane 1), and purified pRK2m3 (Lane 3) as the template. Template DNA containing DNA extracted from the wild-type cells did not produce any amplification (Lane 2). Lane 4 is a DNA ladder.

single metabolic growth mode prohibits comparative "omics" studies and targeted gene deletions to probe $\mathrm{Fe}$ (II) oxidation and carbon flow as mutants defective in these pathways will be unable to grow.

Here we use synthetic biology to study Mariprofundus ferrooxydans PV-1, the founding member of the Zetaproteobacteri $a^{3}$ which are thought to be the dominant $\mathrm{Fe}$ (II) oxidizers in marine environments $\mathrm{s}^{3,11}$. We develop genetic methods and tools to transform $M$. ferrooxydans and manipulate its metabolic capacity by expressing foreign genes, yielding an engineered variant capable of using glucose as a carbon source instead of $\mathrm{CO}_{2}$.

\section{Results and discussion}

We developed a conjugation protocol to successfully transform $M$. ferrooxydans using the donor strain Escherichia coli WM3064, which is auxotrophic for diaminopimelic acid (DAP) ${ }^{15}$. M. ferrooxydans transformed with pRK $2 \mathrm{~m} 3{ }^{16}$ continued to grow and produce characteristic twisted iron oxide stalks ${ }^{3}$ over successive transfers in the presence of kanamycin (Fig. 1a, b). Wild-type cells incubated with kanamycin was unable to grow (data not shown) and only amorphous iron oxyhydroxides were observed (Fig. 1c), likely produced from abiotic Fe(II) oxidation. 16S rRNA gene sequencing confirmed that the transformed culture was $M$. ferrooxydans. After ten transfers, E. coli cells were undetectable by microscopy or growth in lysogeny broth (LB) medium augmented with DAP. Maintenance of pRK2m3 in the transformed $M$. ferrooxydans cells was confirmed by amplifying $330 \mathrm{bp}$ of plasmid specific DNA using total extracted DNA as the template (Fig. 1d) and verified by sequencing. These results demonstrate that $M$. ferrooxydans was able to replicate $\mathrm{pRK} 2 \mathrm{~m} 3$ over repeated transfers under kanamycin selection. With a method for transformation and selection established, we were able to express green fluorescent protein (GFP), encoded by $g f p m u t 2^{17}$ and driven by the $\mathrm{P}_{\text {neo }}$ promoter amplified from upstream the gene encoding kanamycin resistance on pRK2m3. $\mathrm{P}_{\text {neo }}$ was used because it provided sufficient expression to confer kanamycin resistance in $M$. ferrooxydans transformed with the $\mathrm{pRK} 2 \mathrm{~m} 3$ vector. Microscopy confirmed production of GFP in the engineered strain (Fig. 2).

We next sought to leverage our ability to introduce and express foreign genes to augment the metabolism of $M$. ferrooxydans. The M. ferrooxydans PV-1 genome is predicted to encode genes for glycolysis and the Krebs cycle ${ }^{12}$, but lacks genes encoding glucokinase or an apparent glucose transporter. We hypothesized that by introducing the capability to transport and phosphorylate glucose, $M$. ferrooxydans could use it as a carbon and energy source. The genes galP and $g l k$ from $E$. coli, encoding a glucose symporter and glucokinase ${ }^{18}$, were cloned into pRK2m3 

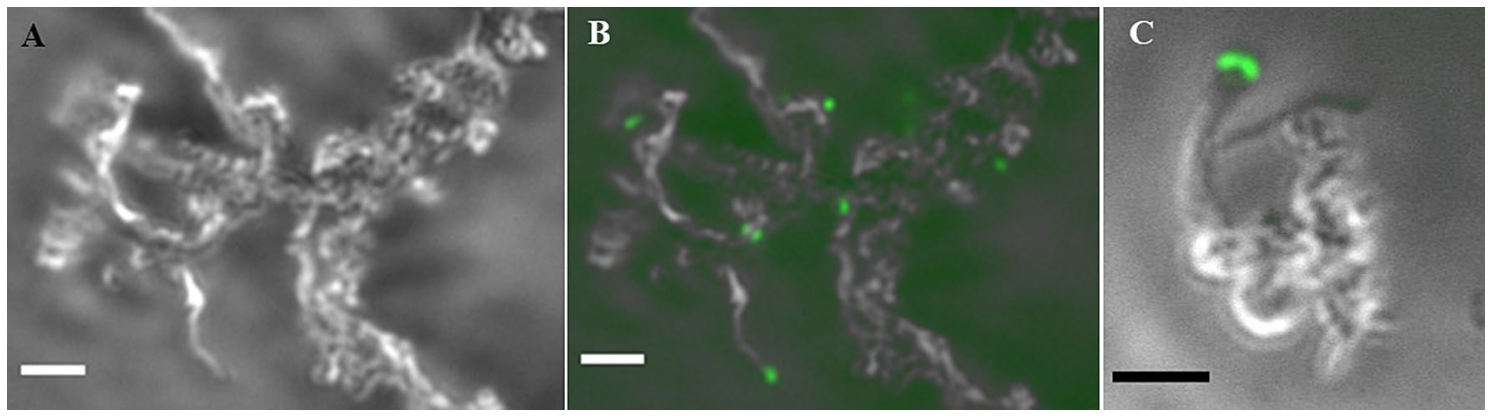

Figure 2. Expression of green fluorescent protein in $M$. ferrooxydans. (a) Light micrograph showing the characteristic twisted stalks produced by $M$. ferrooxydans containing a plasmid with gfpmut 2 and grown in the presence of $200 \mu \mathrm{g} / \mathrm{mL}$ kanamycin. (b,c) Composite images of light and epifluorescent micrographs showing the green fluorescent cells attached to the stalks. Scale bars indicate $5 \mu \mathrm{m}$.

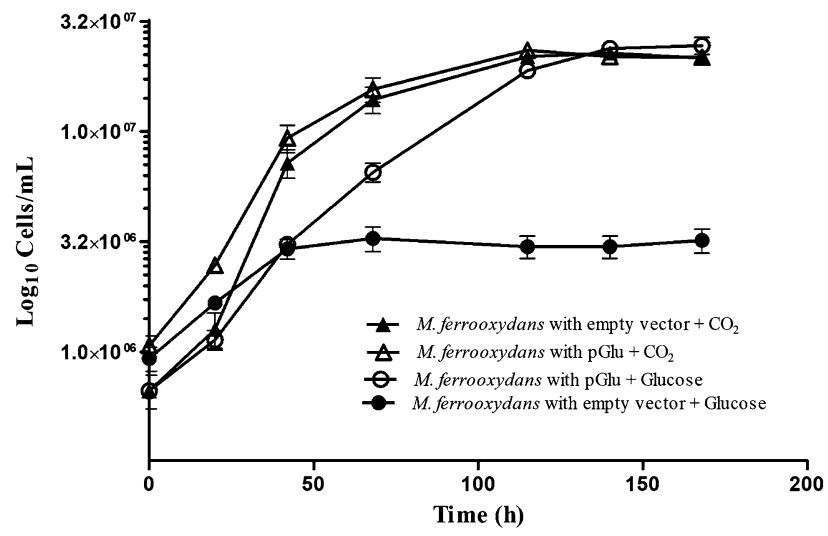

Figure 3. Lithoheterotrophic growth of $M$. ferrooxydans containing pGlu. Growth curves of $M$. ferrooxydans containing pGlu (open symbols) and $M$. ferrooxydans containing empty vector $\mathrm{pRK} 2 \mathrm{~m} 3$ (closed symbols) grown on either glucose $(\mathrm{o}, \boldsymbol{O})$ or carbon dioxide $(\Delta, \boldsymbol{\Delta})$ as the sole carbon source. Error bars represent standard deviation of three replicates.

to create pGlu where each gene was individually driven by $\mathrm{P}_{\text {neo }}$ promoters. $M$. ferrooxydans cells transformed with pGlu did not yield viable cells when selected heterotrophically using glucose (data not shown). However, growth was observed when $M$. ferrooxydans cells transformed with pGlu were selected lithoheterotrophically under Fe(II) oxidizing conditions with glucose as the sole carbon source without the addition of carbon dioxide (Fig. 3). M. ferrooxydans transformed with an empty pRK2m3 vector was unable to grow with glucose as the sole carbon source (Fig. 3). The presence of pGlu was confirmed by amplifying and sequencing galP, glk and the kanamycin resistance cassette using total DNA extracted from transformed glucose-grown cells as template (data not shown). Purity of the transformed cells was confirmed by $16 \mathrm{~S}$ rRNA gene sequencing, microscopy analysis and the absence of bacterial growth in LB medium augmented with DAP.

The rate of $\mathrm{Fe}$ (II) oxidation by the engineered lithoheterotrophic strain was slower during glucose-dependent growth compared to the $\mathrm{Fe}$ (II) oxidation rate during carbon dioxide-dependent growth (Fig. 4). Interestingly, the engineered strain oxidized less total Fe(II) when grown with glucose compared to carbon dioxide (Fig. 4), despite achieving similar final cell densities (Fig. 3). The increase in cell yield per unit Fe(II) oxidized during growth on glucose of the engineered strain can be theoretically attributed to additional energy production from glycolysis and/or biomass precursors provided by glucose.

The inability to transport organic carbon or glycolytic lesions have previously been hypothesized as the reasons for obligate autotrophy in some microorganisms ${ }^{19}$. However, when these deficiencies were addressed using pGlu in M. ferrooxydans, heterotrophic growth was not observed. While the reasons for absence of heterotrophic growth in $M$. ferrooxydans containing pGlu are unknown, we speculate that the cells may either have insufficient flux through glycolysis or that the genes required for glycolysis and anaplerotic reactions are not expressed under the conditions tested. Another possibility could be the inability to convert NADH/NADPH produced by glycolysis into proton motive force (and then ATP). The obligate requirement of Fe(II) as the energy source even while using glucose in the engineered lithoheterotrophic strain provides an important insight into the metabolic functioning of $M$. ferrooxydans where glycolysis seems to be partitioned from energy metabolism. Such a metabolism could be one of the reasons driving obligate lithotrophy in $M$. ferrooxydans. We hypothesize that additional components and alteration of metabolic networks will be required to achieve heterotrophic growth in 


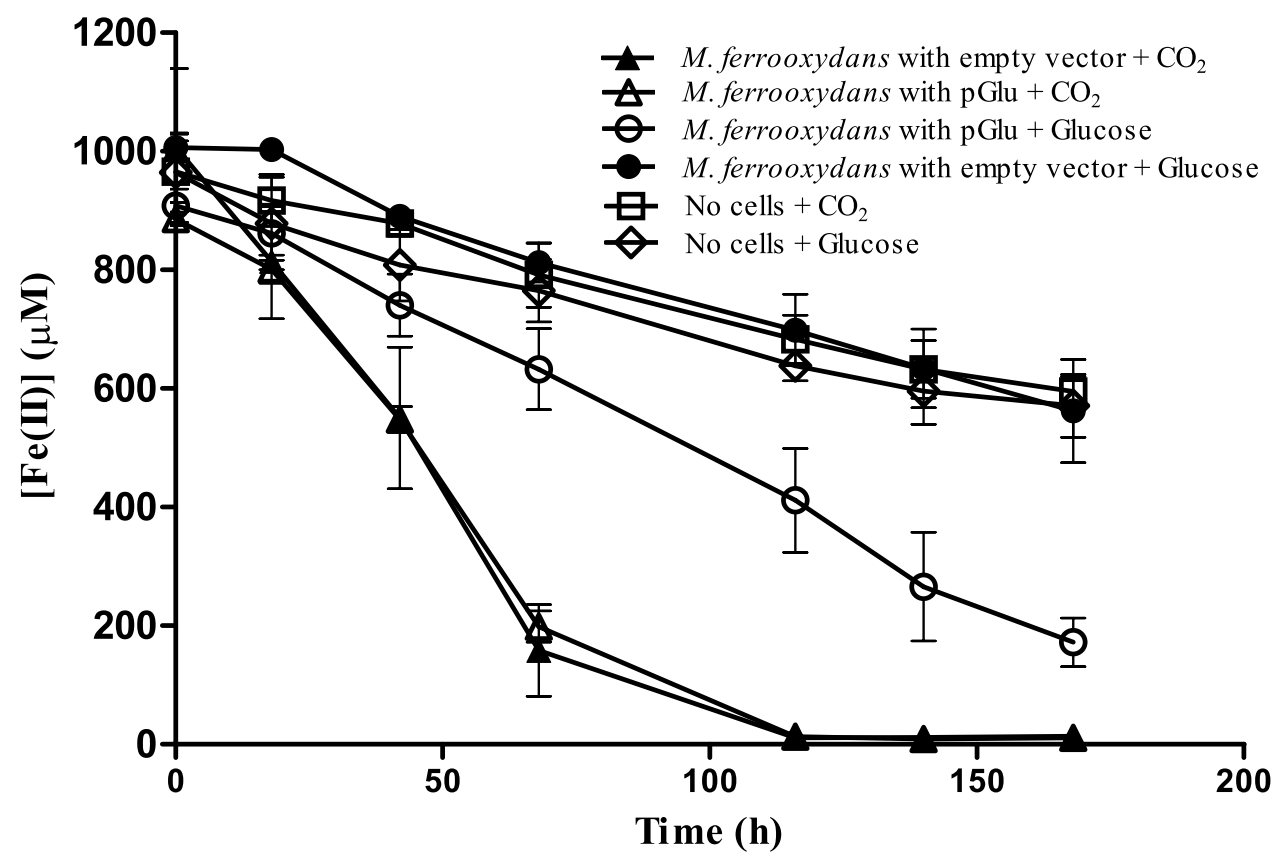

Figure 4. Fe(II) oxidation rate of $M$. ferrooxydans containing pGlu. Fe(II) quantification over time for $M$. ferrooxydans containing pGlu (open symbols) and $M$. ferrooxydans containing empty vector pRK2m3 (closed symbols) grown on either glucose $(\mathrm{o}, \boldsymbol{O})$ or carbon dioxide $(\Delta, \boldsymbol{\Delta})$ as the sole carbon source. Fe(II) was also quantified over time for abiotic treatments in the absence of $M$. ferrooxydans cells, containing either glucose $(\diamond)$ or carbon dioxide $(\square)$ in the medium. Error bars represent standard deviation of three replicates.

M. ferrooxydans, and possibly other obligate chemolithoautotrophs. Although chemolithoheterotrophy, where $\mathrm{Fe}$ (II) oxidation provides energy and organic carbon serves primarily as a carbon source, has been speculated in $\mathrm{Fe}(\mathrm{II})$ oxidizing bacteria ${ }^{20}$, it has not been experimentally validated. Our ability to successfully engineer chemolithoheterotrophy in M. ferrooxydans suggests that other microorganisms in the environment may also be capable of this growth strategy.

Our work provides a proof of concept for using synthetic biology to augment metabolism in microbes with limited or unknown metabolic capabilities to enhance their growth capabilities in laboratory conditions. For example, this approach may be applied to a wide range of bacteria that live by only a single metabolic mode. Additional metabolic enhancement of $M$. ferrooxydans may yield a fully heterotrophic strain that is able to grow without iron oxidation. A heterotrophic strain of $M$. ferrooxydans would grow more robustly, without producing iron oxides as a metabolic byproduct, and be amenable to characterization of genes involved in iron oxidation by mutation. Enhancing the metabolic capabilities of metabolic specialists can provide a way to better understand their physiology and provide a blueprint for their domestication.

\section{Materials and methods}

Bacterial cultivation and DNA extraction. M. ferrooxydans PV-1 was obtained from National Center for Marine Algae and Microbiota culture collection (https://ncma.bigelow.org) and was grown on artificial sea water medium (ASW) ${ }^{3}$, buffered to $\mathrm{pH} 6.5$ with $10 \mathrm{mM}$ MES buffer, using $\mathrm{Fe}(0)$ or $\mathrm{FeCl}_{2}$ as electron donor. When $\mathrm{Fe}(0)$ was used, $M$. ferrooxydans was inoculated into petri plates containing liquid ASW medium and incubated in sealed boxes containing one BD Campy Pack (Catalogue \# 4080) to produce a headspace of $\mathrm{N}_{2}: \mathrm{CO}_{2}: \mathrm{O}_{2}(80: 15: 5)$. When $\mathrm{FeCl}_{2}$ was used, the culture was grown in $1000 \mathrm{~mL}$ serum bottles containing $750 \mathrm{~mL}$ of ASW medium with a headspace of $\mathrm{N}_{2}: \mathrm{CO}_{2}(80: 20)$ and sealed with butyl rubber stoppers. Sealed serum bottles containing the medium were autoclaved and $3 \mathrm{~mL}$ of filtered ferrous chloride solution $(100 \mathrm{mM})$ was added to obtain final $\mathrm{Fe}(\mathrm{II})$ concentration of $400 \mu \mathrm{M}$. $10 \mathrm{~mL}$ of filtered air was added to introduce oxygen as the electron acceptor. $3 \mathrm{~mL}$ of filtered ferrous chloride solution $(100 \mathrm{mM})$, and $10 \mathrm{~mL}$ of filtered air were added to the serum bottles at every $24 \mathrm{~h}$. Growth-curve experiments were performed in $25 \mathrm{~mL}$ Balch tubes containing $10 \mathrm{~mL}$ of the appropriate medium. Balch tubes were sparged with the appropriate gas to remove oxygen and sealed with butyl rubber stoppers. After autoclaving, sealed Balch tubes were added with $100 \mu \mathrm{L}$ of filtered ferrous chloride solution $(100 \mathrm{mM})$ to obtain final $\mathrm{Fe}(\mathrm{II})$ concentration of $1000 \mu \mathrm{M} .0 .5 \mathrm{~mL}$ of filtered air was added to introduce oxygen as electron acceptor. For carbon dioxide dependent growth, ASW medium sparged with $\mathrm{N}_{2}: \mathrm{CO}_{2}(80: 20)$ was used. For glucose dependent growth, ASW medium lacking bicarbonate and augmented with $500 \mu \mathrm{M}$ glucose was sparged with argon gas. To check for glucose dependent growth in the absence of Fe(II), only filtered air was added to the sealed Balch tubes after autoclaving and ferrous chloride was omitted. DNA was extracted from M. ferrooxydans cultures using a Qiagen DNeasy PowerSoil kit. Escherichia coli WM3064 was grown in LB medium containing $360 \mu \mathrm{M}$ DAP. $50 \mu \mathrm{M}$ kanamycin was added to the medium when required. 
Transformation of $M$. ferrooxydans. A $750 \mathrm{~mL}$ culture of $M$. ferrooxydans grown using $\mathrm{FeCl}_{2}$ was centrifuged at $1500 \times \mathrm{rcf}$ for $3 \mathrm{~min}$. The supernatant was then collected and centrifuged at $16,000 \times \operatorname{rcf}$ for $10 \mathrm{~min}$. The pellet obtained was washed with ASW-LB medium (9:1 mixture of ASW and LB) and resuspended in $900 \mu \mathrm{L}$ ASW-LB. One $\mathrm{mL}$ of $E$. coli donor strain culture containing approximately $10^{9}$ cells was washed with LB medium and resuspended in $100 \mu \mathrm{L} \mathrm{LB}$. Donor and recipient cells were mixed and centrifuged at $16,000 \times \mathrm{rcf}$ for $10 \mathrm{~min}$, supernatant removed and $5 \mu \mathrm{L}$ DAP $(360 \mathrm{mM})$ added to the pellet. After incubation at $30^{\circ} \mathrm{C}$ for $18 \mathrm{~h}$, the pellet was washed with ASW medium and transformed cells were selected under iron-oxidizing conditions with $200 \mu \mathrm{g} / \mathrm{mL}$ kanamycin (without DAP), while diluting out untransformed M. ferrooxydans and E. coli cells over successive transfers (each at 1:100 dilution).

Cell and Fe(II) quantification. $\quad 200 \mu \mathrm{L}$ of the sample was collected periodically from the Balch tubes using sterile syringes and needles. $100 \mu \mathrm{L}$ of the sample was added to $900 \mu \mathrm{L}$ of $0.5 \mathrm{~N} \mathrm{HCl}$ to be used for Fe(II) quantification using ferrozine assay ${ }^{21}$ performed in microtiter plates. Cells were fixed in $0.8 \%$ paraformaldehyde for $2 \mathrm{~h}$, stained with $12.5 \mathrm{mM}$ Syto9 and counted using a Petroff-Hausser counting chamber on an epifluorescent microscope.

Plasmid construction. The pRK2m3 plasmid used in this study confers resistance to kanamycin, is approximately $5 \mathrm{~KB}$ in size and contains an origin of transfer (oriT) for conjugative transfer ${ }^{16} \cdot \mathrm{pRK} 2 \mathrm{~m} 3$ is derived from pRK2, which has been shown to be present in low copy in E. coli and Pseudomonas aeruginosa ${ }^{22}$. A 330 bp pRK2m3-specific DNA fragment was amplified using the following primers: CCATGTCGGCAGAAT GCTTA and TGTAAAACGACGGCCAGT. $P_{\text {neo }}$ was amplified from pRK2m3 using pneoF (GATAGAATT CTTGAGACGTTGATCGGCACG) and pneoR (TAGACTCGAGAACACCCCTTGTATTACTGTTTATGT AAGC) primers. To construct the plasmid for GFP expression, $g f p$ mut $2{ }^{17}$ was amplified from pUA66 ${ }^{17}$ using gfpF (ACGACTCGAGATGAGTAAAGGAGAAGAACTTTTCACTGGA) and gfpR (TAGAGAGCTCTTATT TGTACAATTCATCCATACCATGGGTA) primers and cloned into $\mathrm{pRK} 2 \mathrm{~m} 3$ with the $\mathrm{P}_{\text {neo }}$ promoter driving its expression. To construct pGlu, galP and glk were amplified from E. coli K-12 using galPF (ATTTACTAGTAT GCCTGACGCTAAACAGG) /galPR (ATTCGAGCTCTTAATCGTGAGCGCCTATTTCG) and glkF (ACG ACTCGAGATGACAAAGTATGCATTAGTCGGT) /glkR (TAGAGAATTCTTACAGAATGTGACCTAAGG TCTG) primers respectively. Amplified galP and $g l k$ were cloned under the control of separate $\mathrm{P}_{\text {neo }}$ promoters in pRK2m3. All the plasmids were transformed into chemically competent E. coli WM $3064^{15}$ cells, followed by selection on LB plates containing $50 \mu \mathrm{M}$ kanamycin and $360 \mu \mathrm{M}$ DAP.

Received: 12 October 2020; Accepted: 4 January 2021

Published online: 25 January 2021

\section{References}

1. Staley, J. T. \& Konopka, A. Measurement of in situ activities of non-photosynthetic microorganisms in aquatic and terrestrial habitats. Ann. Rev. Microbiol. 39(1), 321-346 (1985).

2. Krepski, S. T., Hanson, T. E. \& Chan, C. S. Isolation and characterization of a novel biomineral stalk-forming iron-oxidizing bacterium from a circumneutral groundwater seep. Environ. Microbiol. 14(7), 1671-1680 (2012).

3. Emerson, D. et al. A novel lineage of proteobacteria involved in formation of marine Fe-oxidizing microbial mat communities. PLoS ONE 2(8), 667 (2007)

4. Quasem, I. et al. Peculiar citric acid cycle of hydrothermal vent chemolithoautotroph Hydrogenovibrio crunogenus, and insights into carbon metabolism by obligate autotrophs. FEMS Microbiol. Let. 364(14), 1148 (2017).

5. Nishihara, H., Igarashi, Y. \& Kodama, T. Hydrogenovibrio marinus gen. nov., sp. nov., a marine obligately chemolithoautotrophic hydrogen-oxidizing bacterium. Int. J. Syst. Evol. Microbiol. 41(1), 130-133 (1991).

6. Shah, V., Chang, B. X. \& Morris, R. M. Cultivation of a chemoautotroph from the SUP05 clade of marine bacteria that produces nitrite and consumes ammonium. ISME J. 11(1), 263 (2017).

7. Emerson, D. \& Moyer, C. Isolation and characterization of novel iron-oxidizing bacteria that grow at circumneutral pH. Appl. Environ. Microbiol. 63(12), 4784-4792 (1997).

8. Weiss, J. V. et al. Characterization of neutrophilic Fe (II)-oxidizing bacteria isolated from the rhizosphere of wetland plants and description of Ferritrophicum radicicola gen. nov. sp. nov., and Sideroxydans paludicola sp. nov.. Geomicrobiol. J. 24(7-8), 559-570 (2007).

9. Neubauer, S. C., Emerson, D. \& Megonigal, J. P. Life at the energetic edge: kinetics of circumneutral iron oxidation by lithotrophic iron-oxidizing bacteria isolated from the wetland-plant rhizosphere. Appl. Environ. Microbiol. 68(8), 3988-3995 (2002).

10. Emerson, D., Fleming, E. J. \& McBeth, J. M. Iron-oxidizing bacteria: an environmental and genomic perspective. Annu. Rev. Microbiol. 64, 561-583 (2010).

11. Emerson, D. Biogeochemistry and microbiology of microaerobic Fe (II) oxidation. Biochem. Soc. Trans. 40(6), 1211-1216 (2012).

12. Singer, E. et al. Mariprofundus ferrooxydans PV-1 the first genome of a marine Fe (II) oxidizing Zetaproteobacterium. PLoS ONE 6(9), 25386 (2011).

13. Kato, S. et al. Comparative genomic insights into ecophysiology of neutrophilic, microaerophilic iron oxidizing bacteria. Front. Microbiol. 6, 1265 (2015).

14. Emerson, D. et al. Comparative genomics of freshwater Fe-oxidizing bacteria: implications for physiology, ecology, and systematics. Front. Microbiol. 4, 254 (2013).

15. Saltikov, C. W. \& Newman, D. K. Genetic identification of a respiratory arsenate reductase. Proc. Natl. Acad. Sci. USA 100(19), 10983-10988 (2003).

16. Chan, C. H., Levar, C. E., Zacharoff, L., Badalamenti, J. P. \& Bond, D. R. Scarless genome editing and stable inducible expression vectors for Geobacter sulfurreducens. Appl. Environ. Microbiol. 81(20), 7178-7186 (2015).

17. Zaslaver, A. et al. A comprehensive library of fluorescent transcriptional reporters for Escherichia coli. Nat. Methods. 3(8), 623 (2006).

18. Hernández-Montalvo, V. et al. Expression of galP and glk in a Escherichia coli PTS mutant restores glucose transport and increases glycolytic flux to fermentation products. Biotechnol. Bioeng. 83(6), 687-694 (2003). 
19. Wood, A. P., Aurikko, J. P. \& Kelly, D. P. A challenge for 21 st century molecular biology and biochemistry: what are the causes of obligate autotrophy and methanotrophy?. FEMS Microbiol. Rev. 28(3), 335-352 (2004).

20. Fleming, E. J. et al. Insights into the fundamental physiology of the uncultured Fe-oxidizing bacterium Leptothrix ochracea. Appl. Environ. Microbiol. 84(9), e02239-e2317 (2018).

21. Stookey, L. L. Ferrozine - a new spectrophotometric reagent for iron. Anal. Chem. 42, 779-781 (1970).

22. Kües, U. \& Stahl, U. Replication of plasmids in gram-negative bacteria. Microbiol. Mol. Biol. Rev. 53(4), 491-516 (1989).

\section{Acknowledgements}

This research was supported by the National Science Foundation Center for Dark Energy Biosphere Investigations (OCE-0939564) post-doctoral fellowship to AJ; and Office of Naval Research Grant N00014-13-10552 and National Science Foundation Grant MCB-1815584 to JAG. This is C-DEBI contribution \#560.

\section{Authors contributions}

A.J. and J.A.G. designed research; A.J. performed research; A.J. and J.A.G. analyzed data and wrote the paper.

\section{Competing interests}

The authors declare no competing interests.

\section{Additional information}

Correspondence and requests for materials should be addressed to J.A.G.

Reprints and permissions information is available at www.nature.com/reprints.

Publisher's note Springer Nature remains neutral with regard to jurisdictional claims in published maps and institutional affiliations.

(c) (i) Open Access This article is licensed under a Creative Commons Attribution 4.0 International License, which permits use, sharing, adaptation, distribution and reproduction in any medium or format, as long as you give appropriate credit to the original author(s) and the source, provide a link to the Creative Commons licence, and indicate if changes were made. The images or other third party material in this article are included in the article's Creative Commons licence, unless indicated otherwise in a credit line to the material. If material is not included in the article's Creative Commons licence and your intended use is not permitted by statutory regulation or exceeds the permitted use, you will need to obtain permission directly from the copyright holder. To view a copy of this licence, visit http://creativecommons.org/licenses/by/4.0/.

(C) The Author(s) 2021 